\title{
Toward an Understanding of Uses and Gratifications Theory and the Sense of Virtual Community on Knowledge Sharing in Online Game Communities
}

\author{
Yu-Wei Chuang
}

\begin{abstract}
Online games have been prevailing over the last decade and becoming a most popular leisure activity. Specifically, one of the recent and favorite types of online games is massively multiplayer online role-playing games (MMORPGs). MMORPGs are very prevalent in the adolescent, resulted from their characteristics, such as network connected, interactive, team-based type, and virtual challenge tasks. Antecedent studies have never thought of uses and gratification approach and the sense of virtual community at the same time when investigating the knowledge sharing in MMORPGs communities; however, the factors of uses and gratification theory will affect knowledge sharing through the sense of virtual community practically. This study is catering to this trend and attempts to build a comprehensive model for capturing the dynamic of knowledge sharing behaviors in MMORPGs communities.
\end{abstract}

Index Terms-Online games, sense of virtual community, uses and gratification theory, knowledge self-efficacy, knowledge sharing.

\section{INTRODUCTION}

Online games have been blossoming over the last decade and have become a popular leisure activity throughout the world. Both mature persons and adolescent are engage in online game [1]. Such games are usually extended from the stand-alone games to the Internet-based games to sustain great amounts of players simultaneously [2]. The Interactive Digital Software Association indicated that there are approximately 145 million Americans who have experiences in playing computer and video games [1]. Additionally, as reported by DFC Intelligence [3] forecast, the worldwide online game market will reach US\$79 billion by 2017 . Particularly, one of the most recent and popular types of online games is massively multiplayer online role-playing games (MMORPGs) [4]. MMORPGs have turned into the most popular and attractive game in the digital games market within the past decade. MMORPGs are the types of continuous, networked, interactive, and team-based game, allowing large amounts of players to interact and play with the others concurrently in the online virtual world [5], [6]. The phenomenon of online gamer's behaviors have been emerged as a crucial issue nowadays.

Manuscript received April 15, 2014; revised June 20, 2014. This research was supported by the Ministry of Science and Technology, Taiwan, R.O.C., under Contract NSC 102-2410-H-126 -016 -

Yu-Wei Chuang is with the Department of Computer Science and Information Management, Providence University, No. 200, Sec. 7, Taiwan Boulevard, Taichung City, 43301, Taiwan (e-mail: ywchuang@gmail.com, ywchuang@pu.edu.tw).
Another recent advance with Internet and information and communication technologies (ICTs) has forged the interested parties to establish virtual communities [7]. Virtual communities refer to the groups of Internet users who repeatedly contact and frequently interact with other people through ICTs within a specified boundary [8], [9]. The aggregations of virtual communities were individuals who establish and maintain personal relationships in cyberspace, which based on common interests, shared values, or goals [7], [10]. In order to enhance individuals' competitiveness in game world, more and more people enthusiastically participate in varieties of virtual communities, especially in MMORPGs communities, for searching, acquiring, and collecting knowledge to resolve problems at game world [11], [12]. Individuals can easily interact with other members across time and space and cooperate with each other to obtain information and knowledge in virtual communities [7], [12]. Accordingly, members will continue to cultivate the intimate connections and deepen the relationships to achieve knowledge exchange and accumulate knowledge assets of their virtual community.

A key determinant of successful virtual communities is knowledge sharing [11], [12]. For a virtual community to be blossoming, knowledge exchange behavior and collaborative activities need to be promoted to build value-based relationships [12]. Through knowledge sharing, community members can not only seek, acquire, and contribute knowledge to cultivate their capabilities, but also build a jointly knowledge base to strengthen mutual understanding and improve communication misapprehension [13], [14]. In other words, a fruitful virtual communities depends on the interaction and knowledge sharing among members, which leads to superior development than others [15].

Recognizing the strategic importance of virtual communities and knowledge sharing, a great range of firms has implemented various knowledge management initiatives. Uses and gratifications theory endeavors to explain what social and psychological needs stimulate audiences to select particular social media (e.g. virtual communities) channels and content choices [16], [17]. Social media not only enable individuals to establish, search, and share knowledge, but also encourage people communicate and cooperate with others [17]. The sense of virtual community refers to the feeling of membership, influence, and immersion to the virtual community. Through the sense of virtual community, individuals concern other members and thereby have willingness to participate in activities and contribute their knowledge in the virtual community [18]. Social cognitive theory suggests that self-efficacy regulates individual 
behavior and activities, which are based on forethought of the trade-offs between required effort and motivation [19], [20]. When the motivation for executing a behavior (e.g., knowledge sharing) is adequate, high levels of perceived self-efficacy will encourage the pursuit of the expected outcomes and overcome the obstacles, meaning that the stronger the perceived self-efficacy, the more effort exerted towards knowledge sharing [19], [20].

These above features afforded by virtual communities and related theories have the potential to influence the knowledge sharing behaviors. If we do not take uses and gratification approach into consideration, the actions in practice cannot be thoroughly described. Therefore, this research presents a research model which integrates uses and gratification theory, the sense of virtual community, and knowledge self-efficacy on knowledge sharing (quality and quantity).

To investigate knowledge sharing in virtual communities in virtual communities, this study extends previous work by drawing from uses and gratifications theory to explain individuals' motivations, the sense of virtual community to describe individuals' internal feeling, as well as social cognitive theory to examine the moderating effects between the sense of virtual community and knowledge sharing in the virtual communities context.

The rest of the paper is organized as follows: the next section presents a brief review of related literature of MMORPGs, sense of virtual communities, uses and gratifications theory, knowledge self-efficacy, and knowledge contribution. In Section III the conceptual model and propositions development. The final section provides a summary and future research direction of this work.

\section{THEORETICAL BACKGROUND}

\section{A. MMORPGS}

Online games refer to the computer games where many people can participate in the meanwhile through online communication platforms [21]. Lu and Wang [22] suggested that online games should have two features, which are 1) players can access to the game directly via the provider's server and the server can automatically update contents of game and fix bugs on a real-time base; 2) players can not only have interaction with other players, but also have exchange behaviors of game information. As mentioned above, MMORPGs games are the most attractive type of online games, resulted from their characteristics of social interaction features and continuous update of new game contents. Online games, especially MMORPGs have become the most popular and prevailing to date. The game companies employed various IT skills, 3D animation, and design approaches to draw players' attention and involvement.

\section{B. Sense of Virtual Community}

The sense of virtual community is a complicated concept [23], which roots in the sense of community developed by McMillan and Chavis [24]. Sense of community refers to the members' feeling of relationship to the community have belonging to a community or individual knowledge of belonging to a collective which include others [25], [26].
Therefore, the concept is regarded as the perception of homogeneity to other members and a recognized joint dependence with other members [25].

The sense of virtual community is defined as "the individual's feelings of membership, influence, and immersion toward a virtual community" [25]. Drawing upon prior research, there are three key elements of the sense of virtual community: 1) membership - individual experiences the feelings of belonging to this virtual community, 2) influence - individual can affect other members in this virtual community, 3) immersion - individual feels the state of flow in the participation of community activities [25], [27].

\section{Uses and Gratifications Theory}

Uses and gratifications theory is used to investigate how social media (e.g. email, BBS, discussion forums, massively multiplayer games, and virtual community) are employed to satisfy individual's needs with different aims [28]. Individuals will choose different social media based on their needs and expect to satisfy their use [28], [29]. Therefore, individuals will look for a social media to gratify their requirements and interests [30]. Moreover, each person has different communication behaviors resulted from their different context and individual factors and thereby influence the gratification degree of individual's needs and interests while utilizing the social media [30], [31].

According to previous research, uses and gratifications theory has three key components: 1) achievement, which refers to the improvement of respect, status, and reputation [30], [32], 2) enjoyment, which indicates the internal satisfaction toward the community [30], [33], and 3) social interaction, which refers to the mutual relationship of community members [30], [34]. Consequently, the uses and gratifications perspective takes an individual view. People will chose different contingencies to adopt appropriate social media to meet their needs. Furthermore, these needs will lead to different cognitive, affective and behavioral results [30], [35].

\section{Social Cognitive Theory and Knowledge Self-Efficacy}

Social cognitive theory suggests that self-efficacy regulates individual behavior and activities, which are based on forethought of the balance between required effort and motivations [19], [20]. When the motivation (e.g. expectations of personal efficacy) of executing a behavior (e.g., knowledge sharing) is adequate, high levels of perceived self-efficacy will encourage the pursuit the expected outcomes and overcome the obstacles, meaning that the stronger the perceived self-efficacy, the more efforts to proceed knowledge sharing [19], [20].

Social cognitive theory is a major theoretical perspective for analyzing individual motivations and behavior [20]. Knowledge self-efficacy is a specific form of the concept of self-efficacy, which are essential determinants of social cognitive theory developed in individual learning and behavior [19], [20]. Knowledge self-efficacy will affect individual behavior by influencing whose beliefs and self-confidence to face the obstacles in knowledge sharing activities. 


\section{PROPOSITION DEVELOPMENT}

\section{A. The Conceptual Model}

In this research, I seek to investigate into following issues: 1) the effect of uses and gratifications (in terms of achievement, enjoyment, and social interaction) on the conduct sense of virtual community, 2) the relationship between the sense of virtual community and knowledge sharing (in terms of quantity and quality), and 3) the moderating effects in the association of sense of virtual community with the knowledge contribution (quantity and quality). Drawing on relevant theories and evidence, the conceptual model of this research is proposed as shown below (Fig. 1).

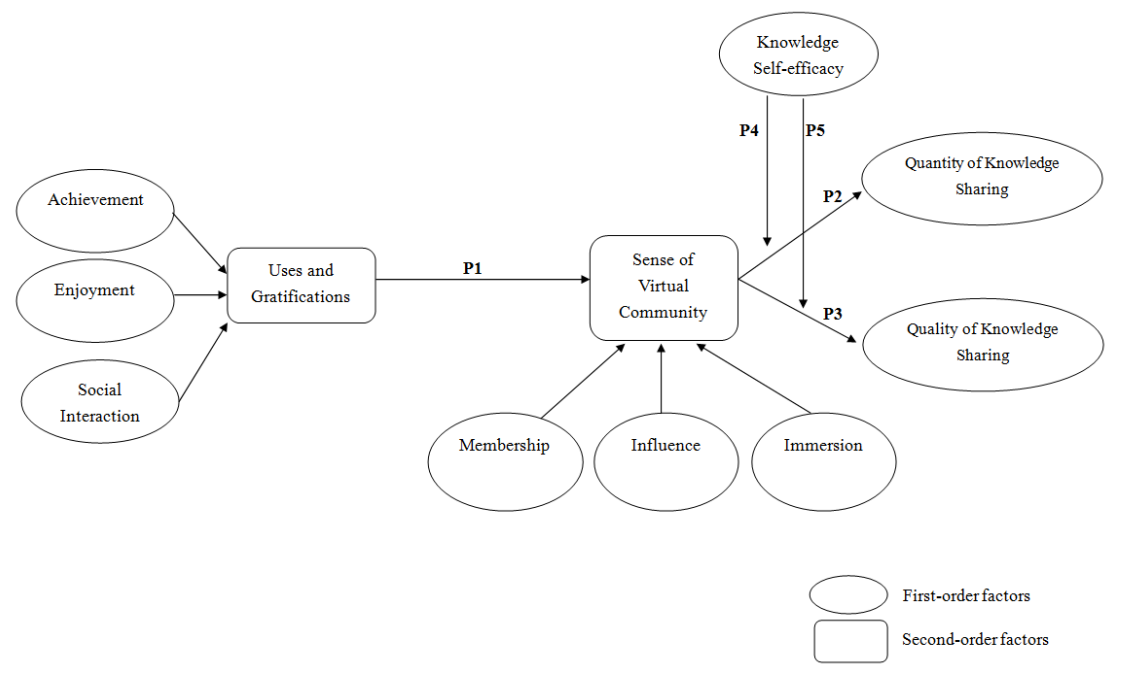

Fig. 1. The conceptual model.

\section{A. The Relationship between Uses and Gratifications and the Sense of Virtual Community}

Drawing upon uses and gratifications approach, people contact and interact with others to reach a sense of belonging [17]. In particular, prior Internet research had demonstrated that social gratifications (e.g. enjoyment of the social ties) will prompt them to use the Internet [36] and take the virtual community as the alternative to interpersonal communication [37]. Furthermore, Park et al., [38] indicated that socializing was regard as a form of gratification which stimulate people actively participate in Facbook using. Dunne et al., [39] suggested that the key determinant of social ties is sustaining and enhancing the relationship with others. Taken as a whole, this study argue that when the social media such as virtual community satisfy the features of uses and gratifications, which potentially encourages the advancement of relationships and increases the sense of belonging of the virtual community. I therefore propose that:

Proposition 1: Uses and gratifications are positively related to the sense of virtual community

\section{B. The Relationship between the Sense of Virtual Community and Knowledge Sharing}

In the virtual community, the sense of belonging means the feeling of membership or identification toward the virtual community. Several scholars further regard it as a sense of virtual community, cultivated in a web-based context [18], [25]. Through the sense of virtual community, individuals concern each other and thereby have willingness to participate more activities in virtual communities [7] and share their knowledge to other members [18]. According to previous research, the sense of belonging in a specific community is suggested to influence the motivation of knowledge sharing [7], [40]. Moreover, Chiu et al., [11] empirically demonstrated that identification which exhibited a sense of belonging toward a virtual community and significantly increased individuals' knowledge contribution [40]. Sharratt and Usoro [41] construct a conceptual model which posited that the stronger sense of community strengthens the knowledge sharing behaviors. Roberts [42] suggested that individuals with a higher sense of belonging will put much effort and time in their online community participation. Based on these arguments, this study suggests that the sense of virtual community increase individuals' knowledge sharing in their virtual community. I therefore hypothesize that:

Proposition 2: The sense of virtual community are positively related to the quantity of knowledge sharing

Proposition 3: The sense of virtual community are positively related to the quality of knowledge sharing

\section{The Moderating Role of Knowledge Self-Efficacy}

Self-efficacy is defined as people's judgment of their capability to execute a particular behavior, which is an essential factor in social psychology. Self-efficacy does not involve the assessment of actual skills people hold, but refers to the self-appraisal of what people believe they can accomplish [19], [43]. Self-efficacy will influence people's behavior by affecting their motivation and confidence to overcome difficulties and improve in performance [43], [44].

Self-efficacy can be either general or specific concept [45]. Thus, knowledge self-efficacy is a specific form of self-efficacy. Knowledge self-efficacy refers to individual believing that his or her knowledge can help to solve task-related problems [45], [46], improve work performance [46], and increase competitive advantage [47]. In this study, through contributing useful and valuable knowledge in response to others' questions, individual will increase their sense of virtual community and knowledge self-efficacy. Taken together, this study argues that knowledge 
self-efficacy has positively moderating effects on the association of the sense of virtual community and knowledge sharing (quantity and quality). Thus, I propose the following hypotheses:

Proposition 4: Knowledge self-efficacy positively moderates the association of the sense of virtual community with the quantity of knowledge sharing.

Proposition 5: Knowledge self-efficacy positively moderates the association of the sense of virtual community with the quality of knowledge sharing.

\section{CONCLUSION}

It is of strategic value for members in virtual communities to understand the factors influencing the development and implementation of knowledge sharing behaviors. Uses and gratifications perspective and the sense of virtual community have been emergent issues in virtual community. In this paper, I developed a research model to depict the role played by uses and gratification theory, the sense of virtual community, knowledge self-efficacy, and knowledge sharing. Uses and gratifications perspective and the sense of virtual community have been emergent topics in virtual community research. This study is in line with the tendency and trying to construct a comprehensive model for seizing the dynamic of knowledge sharing behaviors in MMORPGs communities. The following researcher can adjust or validate the research model I have mentioned and help to develop more in-depth research. The proposed model from this study expects to shed light on future virtual communities' research and offer practical guidelines for practitioners.

\section{ACKNOWLEDGMENT}

This research was supported by the Ministry of Science and Technology, Taiwan, R.O.C., under Contract NSC 102-2410-H-126 -016-.

\section{REFERENCES}

[1] P. Rau, S. Y. Peng, and C. C. Yang, "Time distortion for expert and novice online game players," Cyberpsychology and Behavior, vol. 9, no. 4, pp. 396-403, 2006.

[2] S. Papagiannidis, M. Bourlakis, and F. Li, "Making real money in virtual worlds: MMORPGs and emerging business opportunities, challenges and ethical implications in metaverses," Technological Forecasting and Social Change, vol. 75, pp. 610-622, 2008.

[3] DFC Intelligence. (December 2013). [Online]. Available: http://www.dfcint.com/wp/?p=353,

[4] J. Billieux, M. V. der Linden, S. Achab, Y. Khazaal, L. Paraskevopoulos, D. Zullino, and G. Thorens, "Why do you play World of Warcraft? An in-depth exploration of self-reported motivations to play online and in-game behaviours in the virtual world of Azeroth," Computers in Human Behavior, vol. 29, pp. 103-109, 2013.

[5] M. D. Dickey, "World of Warcraft and the impact of game culture and play in an undergraduate game design course," Computers and Education, vol. 56, pp. 200-209, 2011.

[6] D. S. B. Campello et al., "MMORPGS and cognitive performance: A study with 1280 Brazilian high school students," Computers in Human Behavior, vol. 26, pp. 1564-1573, 2010.

[7] H. H. Teo, H. C. Chan, K. K. Wei, and Z. Zhang, "Evaluating information accessibility and community adaptivity features for sustaining virtual learning communities," International Journal of Human-Computer Studies, vol. 59, pp. 671-697, 2003.

[8] A. L. Blanchard, "Testing a model of sense of virtual community," Computers in Human Behavior, vol. 24, pp. 2107-2123, 2008.
[9] J. L. Welbourne, and A. L. Blanchard, and M. B. Wadsworth, "Motivations in virtual health communities and their relationship to community, connectedness and stress," Computers in Human Behavior, vol. 29, no. 1, pp. 129-139, 2013.

[10] T. J. Spaulding, "How can virtual communities create value for business?" Electronic Commerce Research and Applications, vol. 9, pp.38-49, 2010.

[11] C. M. Chiu, M. H. Hsu, and E. T. G. Wang, "Understanding knowledge sharing in virtual communities: an integration of social capital and social cognitive theories," Decision Support Systems, vol. 42, no. 3, pp. 1872-1888, 2006.

[12] M. J. Lin, S. W. Hung, and C. J. Chen, "Fostering the determinants of knowledge sharing in professional virtual communities," Computers in Human Behavior, vol. 25, pp. 929-939, 2009.

[13] A. Cabrera, W. C. Collins, and J. F. Salgado, "Determinants of individual engagement in knowledge sharing," International Journal of Human Resource Management, vol. 17, no. 2, pp. 245-264, 2006.

[14] Y. Liu and J. S. Phillips, "Examining the antecedents of knowledge sharing in facilitating team innovativeness from a multilevel perspective," International Journal of Information Management, vol. 31, pp. 44-52, 2011.

[15] M. R. Tagliaventi, F. Bertolotti, and D. M. Macrı, "A perspective on practice in interunit knowledge sharing," European Management Journal, vol. 28, pp. 331-345, 2010.

[16] A. Diddi and R. LaRose, "Getting hooked on news: Uses and gratifications and the formation of news habits among college students in an Internet environment," Journal of Broadcasting and Electronic Media, vol. 50, no. 2, pp. 193-210, 2006.

[17] C. S. Lee and L. Ma, "News sharing in social media: The effect of gratifications and prior experience," Computers in Human Behavior, vol. 28, pp. 331-339, 2012.

[18] L. Zhao, Y. Lu, B. Wang, P. Y. K. Chau, and L. Zhang, "Cultivating the sense of belonging and motivating user participation in virtual communities: A social capital perspective," International Journal of Information Management, vol. 32, no. 6, pp. 574-588, 2012.

[19] A. Bandura, Social foundations of thought and action: A social cognitive theory, Englewood Cliffs, NJ: Prentice-Hall, 1986.

[20] J. He and L. A. Freeman, "Understanding the formation of general computer self-efficacy," Communications of the Association for Information Systems, vol. 26, pp. 225-244, 2010.

[21] K. H. Kim, J. Y. Park, D. Y. Kim, H. I. Moon, and H. C. Chun, "E-lifestyle and motives to use online games," Irish Marketing Review, vol. 15, no. 2, pp. 71-77, 2002.

[22] H. P. Lu and S. M. Wang, "The role of Internet addiction in online game loyalty: an exploratory study," Internet Research, vol. 18, no. 5, pp. 499-519, 2008 .

[23] L. Tonteri, M. Kosonen, H. K. Ellonen, and A. Tarkiainen, "Antecedents of an experienced sense of virtual community," Computers in Human Behavior, vol. 27, pp. 2215-2223, 2011.

[24] D. W. McMillan and D. M. Chavis, "Sense of community: A definition and theory," Journal of Community Psychology, vol. 14, no. 1, pp. 6-23, 1986.

[25] J. Koh and Y. G. Kim, "Sense of Virtual Community: A Conceptual Framework and Empirical Validation," International Journal of Electronic Commerce, vol. 8, no. 2, pp. 75-93, 2003.

[26] J. R. Newbrough and D. M. Chavis, "Psychological sense of community," American Journal of Community Psychology, vol. 14, no. 1, pp. 3-5, 1986.

[27] Y. H. Tsai, S. W. Joe et al., "Modeling the relationship between IT-mediated social capital and social support: Key mediating mechanisms of sense of group," Technological Forecasting and Social Change, vol. 79, pp. 1592-1604, 2012.

[28] E. M. Perse and J. A. Courtright, "Normative images of communication media: Mass and interpersonal channels in the new media environment," Human Communication Research, vol. 19, pp. 485-503, 1993.

[29] A. D. Smock, N. Ellison, C. Lampe, and D. Y. Wohn, "Facebook as a toolkit: A uses and gratification approach to unbundling feature use," Computers in Human Behavior, vol. 27, pp. 2322-2329, 2011.

[30] J. H. Wu, S. C. Wang, and H. H. Tsai, "Falling in love with online games: The uses and gratifications perspective," Computers in Human Behavior, vol. 26, pp. 1862-1871, 2010.

[31] A. M. Rubin, "Uses-and-Gratifications perspective on media effects," in J. Bryant and M. B. Oliver (Eds.), Media effects: Advances in Theory and Research, pp. 165-184, NY: Routledge, 2009.

[32] M. M. Wasko and S. Faraj, "Why should I share? Examining social capital and knowledge contribution in electronic networks of practice," MIS Quarterly, vol. 29, no. 1, pp. 35-57, 2005. 
[33] D. K. Koo, "The moderating role of locus of control on the links between experiential motives and intention to play online games," Computers in Human Behavior, vol. 25, no. 2, pp. 466-474, 2009

[34] N. Yee, "Motivations for play in online games," CyberPsychology and Behavior, vol. 9, no. 6, 772-775, 2006.

[35] V. Pornsakulvanich, P. Haridakis, and A. M. Rubin, "The influence of dispositions and Internet motivation on online communication satisfaction and relationship closeness," Computers in Human Behavior, vol. 24, no. 5, pp. 2292-2310, 2008.

[36] R. LaRose and M. S. Eastin, "A social cognitive theory of Internet uses and gratifications: Toward a new model of media attendance," Journal of Broadcasting and Electronic Media, vol. 48, no. 3, pp.358-377, 2004.

[37] Z. Papacharissi and A. M. Rubin, "Predictors of Internet use," Journal of Broadcasting and Electronic Media, vol. 44, no. 2, pp. 175-196, 2000.

[38] N. Park, K. F. Kee, and S. Valenzuela, "Being immersed in social networking environment: Facebook groups, uses and gratifications, and social outcomes," CyberPsychology and Behavior, vol. 12, no. 6, pp. 729-733, 2009.

[39] A. Dunne, M. Lawlor, and J. Rowley, "Young people's use of online social networking sites - A uses and gratifications perspective," Journal of Research in Interactive Marketing, vol. 4, no. 1, pp. 46-58, 2010.

[40] S. Chai, and M. Kim, "A socio-technical approach to knowledge contribution behavior: An empirical investigation of social networking sites users," International Journal of Information Management, vol. 32, pp. 118-126, 2012.

[41] M. Sharratt and A. Usoro, "Understanding knowledge-sharing in online communities of practice," Electronic Journal on Knowledge Management, vol. 1, pp. 187-196, 2003.
[42] T. L. Roberts, "Are newsgroups virtual communities?" in Proc. CHI 98 Conference on Human Factors in Computing Systems, pp. 360-367, 1998.

[43] D. R. Compeau and C. A. Higgins, "Computer self-efficacy: Development of a measure and initial test," MIS Quarterly, vol. 19, no. 2, pp. 189-211, 1995.

[44] B. Hasan, "Delineating the effects of general and system-specific computer self-efficacy beliefs on IS acceptance," Information and Management, vol. 43, pp. 565-571, 2006.

[45] A. Kankanhalli, B. C. Y. Tan, and K. K. Wei, "Contributing knowledge to electronic repositories: An empirical investigation," MIS Quarterly, vol. 29 , no. 1, pp. 113-143, 2005.

[46] S. Ba, J. Stallaert, and A. B. Whinston, "Research commentary: Introducing a third dimension in information systems design - the case for incentive alignment," Information Systems Research, vol. 12, no. 3, pp. 225-239, 2001

[47] M. M. Wasko, and S. Faraj, "It is what one does: Why people participate and help others in electronic communities of practice," Journal of Strategic Information Systems, vol. 9, pp. 155-173, 2000.

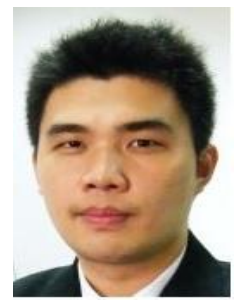

Yu-Wei Chuang is an assistant professor of the Department of Computer Science and Information Management at Providence University in Taiwan. He received his $\mathrm{Ph} . \mathrm{D}$. in business administration from National Central University. His research interests include knowledge management, virtual communities, inter-organizational relationship, and social psychology. His papers have appeared in knowledge-based systems, wseas transactions on systems, lecture notes in computer science series, and various conference proceedings. 